Original Article

\title{
Comparative study on isokinetic capacity of knee and ankle joints by functional injury
}

\author{
Kyoungkyu Jeon, $\mathrm{PhD}^{1)}$, Byoung-Do Seo, MS, PT ${ }^{2)}$, SAng-Ho Lee, $\mathrm{PhD}^{3)^{*}}$ \\ 1) Sport Science Institute, Incheon National University, Republic of Korea \\ 2) Department of Physical Therapy, College of Health, Kyungwoon University, Republic of Korea \\ 3) Department of Physical Education, College of Education, Hankuk University of Foreign Studies: \\ 107 Imun-ro, Dongdaemun-gu, Seoul 02450, Republic of Korea
}

\begin{abstract}
Purpose] To collect basic data for exercise programs designed to enhance functional knee and ankle joint stability based on isokinetic measurement and muscle strength evaluations in normal and impaired functional states. [Subjects and Methods] Twenty-four subjects were randomly assigned to the athlete group and the control group $(\mathrm{n}=12 \mathrm{each})$. Data were collected of isokinetic knee extensor and flexor strength at $60 \% \mathrm{sec}, 180 \% \mathrm{sec}$, and $240 \% \mathrm{sec}$ and ankle plantar and dorsiflexor strength at $30 \% \mathrm{sec}$ and $120 \% \mathrm{sec}$. [Results] Significant intergroup differences were observed in peak torque of the right extensors at $60 \% \mathrm{sec}, 180 \% \mathrm{sec}$, and $240 \% \mathrm{sec}$ and the right flexors at $240 \%$ sec. Significant differences were observed in peak torque/body weight in the right extensors at $60 \%$ sec, $180 \%$ $\mathrm{sec}$, and $240 \% \mathrm{sec}$ and in the right flexors at $180 \% \mathrm{sec}$ and $240 \% \mathrm{sec}$. Significant peak torque differences were noted in the left ankle joint dorsiflexor at $30 \% \mathrm{sec}$ and $120 \% \mathrm{sec}$, right plantar flexor at $120 \% \mathrm{sec}$, left plantar flexor at $30 \%$ sec, left dorsiflexor at $30 \% \mathrm{sec}$ and $120 \% \mathrm{sec}$, and right dorsiflexor at $120 \% \mathrm{sec}$. [Conclusion] Isokinetic evaluation stimulates muscle contraction at motion-dependent speeds and may contribute to the development of intervention programs to improve knee and ankle joint function and correct lower-extremity instability.

Key words: Isokinetic, Knee and ankle joints, Functional injury
\end{abstract}

(This article was submitted Sep. 16, 2015, and was accepted Oct. 16, 2015)

\section{INTRODUCTION}

Dynamic knee stability is defined as the state responding to the proprioceptive feedback alerted by recurring postural instability caused by limited range of motion (ROM) and restricted movement ${ }^{1}$. Pain and functional instability are the most common pathological conditions of the knee joint. Mechanical knee joint injuries are primarily associated with meniscal lesions, and knee pain and mechanical disorders are easily overlooked ${ }^{2}$. Recurring disorders arising from diminished ROM and muscle strength are reportedly caused by altered muscular reflexes of the tissues surrounding the knee joint due to early trauma or chronic damage and insufficient proprioception ${ }^{3}$. Muscular stability, especially that of the quadriceps, is essential for functional recovery of the knee joint ${ }^{4,5}$, and knee bone malalignment, overstress, and muscular weakness around the hip joints are the most common causes of functional abnormalities ${ }^{6-8)}$. Knee instability can lead to lower-limb collapse due to the pain control mechanism of the quadriceps femoris under patellofemoral joint loading in an upright standing position. Pain in the knee joint can be caused by accumulated injuries, traumatic patellar dislocation, knee bone malalignment, increased compressive pressure due to obesity or load-lifting, and primary knee osteoarthritis, which can lead to secondary knee osteoarthritis and is likely to be accelerated by obesity ${ }^{9}$.

The ankle joint has various functions, such as weight-bearing, static and dynamic motion and control, walking, running, jumping, landing from a jump, and shock absorption. It also plays an important role in ensuring a stable base of support and flexibility through biomechanical compensation in motions coordinated by the knee and hip joints ${ }^{10)}$. Functional ankle

*Corresponding author. Sang-Ho Lee (E-mail: sm5206027@naver.com)

(C2016 The Society of Physical Therapy Science. Published by IPEC Inc.

This is an open-access article distributed under the terms of the Creative Commons Attribution Non-Commercial No Derivatives (by-nc-nd) License $<$ http://creativecommons.org/licenses/by-nc-nd/3.0/>. 
instability is a condition of ankle joint weakness ("give way" feeling) without a structural problem due to recurrent ankle sprains or high-intensity track and field exercises. Not only does it cause recalcitrant chronic problems for athletes, it can also manifest as lesions with many different forms ${ }^{11}{ }^{12}$. Hertel noted that chronic ankle instability is associated with several functional impairments, such as decreased muscle strength, affected proprioception, inadequate neuromuscular control, and postural control loss ${ }^{13}$. The results of recurrent and chronic ankle sprains can be classified into diminished ROM, anthropometric changes, ligament laxity, and regenerative changes. Functional ankle instability can be classified as changes that affect stability due to the lack of dynamic postural control during functional motions including walking ${ }^{14,15)}$. Appropriate muscle contractility is an efficient indicator of muscular function for athletes and non-athletes alike ${ }^{16,17)}$ and can be safely and simply applied to muscle imbalance correction and muscle damage recovery interventions.

Based on these theoretical factors, this study aimed to establish basic data that may be efficiently applied to the development of exercise programs designed to improve the functional stability of the knee and ankle joints. To this end, we performed isokinetic measurements and evaluated knee and ankle muscle strength in functionally intact and affected states to identify problems during functional activities in the lower limb joints and muscles.

\section{SUBJECTS AND METHODS}

For the experiments in this study, we enrolled 12 male high school athletes (five basketball and seven volleyball players) who had been treated in the hospital for functional instability of the knee and ankle joints in the preceding 12 months as well as 12 age- and gender-matched healthy controls. All 24 subjects were right-handed. The subjects provided written informed consent prior to participating. The study was approved by the HUFS University and the institution in which it was performed and complied with the ethical standards of the Declaration of Helsinki. The subjects' general characteristics are shown in Table 1 .

The isokinetic strength variables of the knee and ankle joints were measured using the Humac Norm Testing \& Rehabilitation System (CSMi, USA). The experimental procedure and measurement setup for the knee joint were as follows. The subject was seated on the measurement chair, and the knee positions were adjusted using a table-tube cross-clamp and a pedestal column clamp to align the axis of rotation of the knee joints with that of the isokinetic dynamometer. The thighs and trunk were firmly fastened using straps and belts to prevent the parts other than the target joints from exerting external force on the muscular motions of the thighs during the knee flexion and extension exercises. During the knee flexion and extension exercises, muscle activation of the target region was facilitated by adjusting the lengths for the lower legs and the adjustment axis using a long input adapter and an adjusting arm followed by fixing of the ankle region with Velcro straps. The subject was requested to execute knee joint flexion and extension from $135^{\circ}$ to $0^{\circ}$ and from $0^{\circ}$ to $135^{\circ}$, respectively, whereby the ROM was controlled to prevent hyperextension or hyperflexion. Prior to the measurement sessions, the subjects performed pre-speed warm-ups in which they performed three submaximal and one maximal flexion and extension exercise at loading speeds of $60^{\circ} / \mathrm{sec}$ (five repetitions), $180^{\circ} / \mathrm{sec}$ (10 repetitions), and $240^{\circ} / \mathrm{sec}$ (20 repetitions) with a 2-min rest after each measurement.

Ankle joint plantar- and dorsiflexion strengths were measured at $30 \% \mathrm{sec}$ and $120 \% \mathrm{sec}$ as described above. Measurements were performed in each group after pre-speed warm-ups in which the subjects underwent three submaximal and one maximal ankle plantar- and dorsiflexion exercises at speeds of $30 \% \mathrm{sec}$ (five repetitions) and $120 \% \mathrm{sec}$ (15 repetitions) with a 2-min rest after each measurement. The researcher verbally encouraged the subjects to perform the exercises to their maximum capacity for all measurements.

The measurement results were processed by SPSS for Windows version 20.0 software (SPSS Inc., USA). Mean and standard deviation were calculated for each measurement variable, and intergroup differences were analyzed using independent t-tests with the statistical significance level set to $\mathrm{p}<0.05$.

\section{RESULTS}

The peak torque measurements for the knee joint revealed statistically significant intergroup differences between the functionally affected athlete group and the healthy control group for right extensor strength at $60^{\circ} / \mathrm{sec}, 180^{\circ} / \mathrm{sec}$, and $240^{\circ} /$ $\mathrm{sec}$ as well as right flexor strength at $240^{\circ} \mathrm{sec}$, while the remaining variables showed no statistically significant intergroup differences (Table 2). For peak torque/body weight (PTBW), intergroup differences were observed for right extensor strength at $60^{\circ} / \mathrm{sec}, 180^{\circ} / \mathrm{sec}$, and $240^{\circ} / \mathrm{sec}$ and for right flexor strength at $180^{\circ} / \mathrm{sec}$ and $240^{\circ} / \mathrm{sec}$ (Table 3). Comparison of left $/$ right peak torque ratios did not yield statistically significant differences for any of the variables at exercise speeds of $60^{\circ} / \mathrm{sec}, 180^{\circ} /$ sec, and $240^{\circ} / \mathrm{sec}$ (Table 4 ).

The peak torque measurements for the ankle joint revealed statistically significant intergroup differences between the affected and healthy groups for left dorsiflexor strength at $30 \% \mathrm{sec}$ and $120 \% \mathrm{sec}$ and for right plantar flexor strength at $120 \% \mathrm{sec}$ (Table 5). For PTBW, intergroup differences were observed for left plantar flexor strength at $30^{\circ} / \mathrm{sec}$, left dorsiflexor strength at $30 \% \mathrm{sec}$ and $120 \% \mathrm{sec}$, and right dorsiflexor strength at $120 \% \mathrm{sec}$ (Table 6). Comparison of left/right peak torque ratios did not yield any statistically significant differences at $30 \% \mathrm{sec}$ and $120 \% \mathrm{sec}$ (Table 7). 
Table 1. Subjects' general characteristics

\begin{tabular}{llccc}
\hline Group & N & Age (yrs) & Height $(\mathrm{cm})$ & Weight $(\mathrm{kg})$ \\
\hline Athlete & 12 & $16.8 \pm 1.9$ & $181.1 \pm 5.5$ & $71.1 \pm 8.6$ \\
Control & 12 & $20.3 \pm 1.5$ & $177.3 \pm 6.8$ & $72.2 \pm 7.5$ \\
Total & 24 & $18.6 \pm 2.4$ & $179.2 \pm 6.3$ & $71.6 \pm 7.9$ \\
\hline
\end{tabular}

Values are mean \pm SD

Table 2. Comparison of peak torque of the knee joint

\begin{tabular}{llcc}
\hline Variable & & Athlete group & Control group \\
\hline Extensors (Nm) at $60^{\circ}$ & Right & $232.1 \pm 72.1$ & $179.8 \pm 28.6^{*}$ \\
& Left & $156.3 \pm 69.1$ & $178.1 \pm 34.2$ \\
Flexors (Nm) at $60^{\circ}$ & Right & $135.5 \pm 32.2$ & $119.7 \pm 26.3$ \\
& Left & $96.4 \pm 38.2$ & $108.4 \pm 23.9$ \\
Extensors (Nm) at $180^{\circ}$ & Right & $134.6 \pm 42.8$ & $100.5 \pm 19.1^{*}$ \\
& Left & $90.0 \pm 41.4$ & $96.3 \pm 18.7$ \\
Flexors (Nm) at $180^{\circ}$ & Right & $89.6 \pm 24.8$ & $73.0 \pm 15.8$ \\
& Left & $72.6 \pm 32.4$ & $67.6 \pm 14.5$ \\
Extensors (Nm) at $240^{\circ}$ & Right & $112.0 \pm 27.8$ & $79.4 \pm 14.6^{* *}$ \\
& Left & $80.2 \pm 27.0$ & $80.6 \pm 13.5$ \\
Flexors (Nm) at $240^{\circ}$ & Right & $85.2 \pm 25.0$ & $67.1 \pm 9.3^{*}$ \\
& Left & $67.5 \pm 30.1$ & $59.8 \pm 12.9$ \\
\hline
\end{tabular}

Values are mean $\pm \mathrm{SD} ;{ }^{*} \mathrm{p}<0.05, * * \mathrm{p}<0.01$

Table 3. Comparison of peak torque/body weight of the knee joint

\begin{tabular}{|c|c|c|c|}
\hline Variable & & Athlete group & Control group \\
\hline \multirow[t]{2}{*}{ Extensors $(\%)$ at $60^{\circ}$} & Right & $325.7 \pm 81.0$ & $251.5 \pm 41.3^{*}$ \\
\hline & Left & $217.8 \pm 74.0$ & $222.8 \pm 70.4$ \\
\hline \multirow[t]{2}{*}{ Flexors $(\%)$ at $60^{\circ}$} & Right & $193.3 \pm 32.6$ & $166.4 \pm 35.6$ \\
\hline & Left & $133.8 \pm 41.9$ & $137.6 \pm 47.6$ \\
\hline \multirow[t]{2}{*}{ Extensors $(\%)$ at $180^{\circ}$} & Right & $188.8 \pm 50.3$ & $140.5 \pm 28.7^{* *}$ \\
\hline & Left & $124.7 \pm 42.8$ & $123.2 \pm 46.7$ \\
\hline \multirow[t]{2}{*}{ Flexors $(\%)$ at $180^{\circ}$} & Right & $125.3 \pm 26.4$ & $98.5 \pm 25.0^{*}$ \\
\hline & Left & $99.9 \pm 35.9$ & $86.3 \pm 32.0$ \\
\hline \multirow[t]{2}{*}{ Extensors $(\%)$ at $240^{\circ}$} & Right & $157.5 \pm 34.3$ & $111.9 \pm 24.5^{* *}$ \\
\hline & Left & $112.3 \pm 28.7$ & $103.2 \pm 37.1$ \\
\hline \multirow[t]{2}{*}{ Flexors $(\%)$ at $240^{\circ}$} & Right & $118.8 \pm 27.9$ & $93.6 \pm 13.8^{*}$ \\
\hline & Left & $92.8 \pm 33.1$ & $76.9 \pm 27.8$ \\
\hline
\end{tabular}

Values are mean $\pm \mathrm{SD} ;{ }^{*} \mathrm{p}<0.05,{ }^{* *} \mathrm{p}<0.01$

Table 4. Comparison of bilateral balance ratio of the knee joint

\begin{tabular}{llcc}
\hline Variable & & Athlete group & Control group \\
\hline Ratio (\%) at $60^{\circ}$ & Right & $61.6 \pm 14.4$ & $67.0 \pm 16.0$ \\
& Left & $63.5 \pm 16.1$ & $61.2 \pm 8.8$ \\
Ratio (\%) at $180^{\circ}$ & Right & $68.8 \pm 13.6$ & $72.3 \pm 14.8$ \\
& Left & $81.6 \pm 22.5$ & $71.0 \pm 12.8$ \\
Ratio (\%) at $240^{\circ}$ & Right & $77.3 \pm 17.9$ & $86.4 \pm 17.4$ \\
& Left & $84.5 \pm 26.7$ & $75.1 \pm 17.0$ \\
\hline
\end{tabular}

Values are mean $\pm \mathrm{SD}$ 
Table 5. Comparison of peak torque of the ankle joint

\begin{tabular}{llcc}
\hline Variable & & Athlete group & Control group \\
\hline Plantarflexors $(\mathrm{Nm})$ at $30^{\circ}$ & Right & $73.5 \pm 26.4$ & $66.9 \pm 21.3$ \\
& Left & $51.6 \pm 24.2$ & $68.0 \pm 21.1$ \\
Dorsiflexors (Nm) at $30^{\circ}$ & Right & $30.3 \pm 5.0$ & $29.6 \pm 3.6$ \\
& Left & $19.4 \pm 4.4$ & $29.7 \pm 5.9^{* * *}$ \\
Plantarflexors (Nm) at $120^{\circ}$ & Right & $39.9 \pm 14.7$ & $38.8 \pm 18.5$ \\
& Left & $29.7 \pm 15.4$ & $35.2 \pm 12.2$ \\
Dorsiflexors $(\mathrm{Nm})$ at $120^{\circ}$ & Right & $16.0 \pm 3.0$ & $13.3 \pm 2.2^{*}$ \\
& Left & $9.8 \pm 2.3$ & $13.8 \pm 4.7^{*}$ \\
\hline
\end{tabular}

Values are mean $\pm \mathrm{SD} ;{ }^{*} \mathrm{p}<0.05,{ }^{* * *} \mathrm{p}<0.00$

Table 6. Comparison of peak torque/body weight of the ankle joint

\begin{tabular}{lllcc}
\hline \multicolumn{2}{l}{ Variable } & & Athlete group & Control group \\
\hline 30 & Plantarflexors (\%) & Right & $103.4 \pm 32.5$ & $92.3 \pm 25.0$ \\
& & Left & $71.1 \pm 26.1$ & $94.7 \pm 27.4^{*}$ \\
& \multirow{2}{*}{ Dorsiflexors (\%) } & Right & $42.8 \pm 6.2$ & $41.5 \pm 4.9$ \\
& & Left & $27.5 \pm 5.8$ & $42.5 \pm 11.2^{* * *}$ \\
120 & Plantarflexors (\%) & Right & $56.8 \pm 19.4$ & $53.7 \pm 24.5$ \\
& & Left & $41.5 \pm 18.5$ & $50.4 \pm 20.5$ \\
& \multirow{2}{*}{ Dorsiflexors (\%) } & Right & $23.0 \pm 5.0$ & $18.5 \pm 3.6^{*}$ \\
& & Left & $14.3 \pm 2.9$ & $19.8 \pm 8.0^{*}$ \\
\hline
\end{tabular}

Values are mean $\pm \mathrm{SD} ; * \mathrm{p}<0.05, * * * \mathrm{p}<0.00$

Table 7. Comparison of bilateral balance ratio of the ankle joint

\begin{tabular}{llcc}
\hline Variable & & Athlete group & Control group \\
\hline Ratio (\%) at $30^{\circ}$ & Right & $46.0 \pm 17.4$ & $48.0 \pm 15.3$ \\
& Left & $43.2 \pm 14.2$ & $51.7 \pm 30.8$ \\
Ratio (\%) at $120^{\circ}$ & Right & $43.3 \pm 14.5$ & $44.5 \pm 26.8$ \\
& Left & $42.9 \pm 24.4$ & $46.4 \pm 26.2$ \\
\hline
\end{tabular}

Values are mean \pm SD

\section{DISCUSSION}

Peak torque of the lower limbs and bilateral balance ratios are most commonly used to assess the isokinetic strength of the lower limb muscles, detect injuries, and predict risk ${ }^{18)}$. Jumping is one of the most common motions, and the landing or directional change after jumping motion should be executed fluidly and stably under conditions of adequate muscle activation with components of complex muscle extension and flexion movements ${ }^{19}$. Jumping height depends on flexion and extension of the knee and ankle joints, and repeated excessive use of the lower limb joints is considered responsible for $50-80 \%$ of injuries $^{20)}$.

The knee joint can extend and flex to execute stable motions. Extension is primarily performed by the quadriceps femoris muscle, which is also responsible for the weight-bearing and postural balance used for body axis alignment, stability, and walking ${ }^{21-23)}$. Damage to the knee joint in particular is likely to increase postural imbalance and falling risk by inducing abnormal responses in the muscles surrounding the knee including loss of muscle strength and subsequent fatigue. Kim performed a large-scale 2 year prospective cohort study of 1,060 Korean male professional volleyball players that focused on injury sites and types and found that the lower extremities sustained $63.4 \%$ of all injuries, with the knee showing the highest risk of injury, followed by the ankle, lower leg, thigh, and foot. In a 4 year study on injuries among female college volleyball players ${ }^{24)}$, Agel et al. also reported lower extremity injury rates of $58.7 \%$ during the season and $55.9 \%$ during training ${ }^{25)}$. Given that muscle performance in jumping significantly relies upon lower-extremity extension strength in the knee and then the ankle joint, identifying muscle performance abnormalities may be useful for determining the causes of imbalance- 
induced functional instability and creating corrective strategies ${ }^{26)}$. In a study in soccer players, Choi et al. reported significant differences between knee extensor and flexor isokinetic strength $(247.9 \pm 34.4 \mathrm{Nm}$ vs. $165.1 \pm 29.4 \mathrm{Nm})$ and ascribed higher flexor strength in high-performing players to the fact that knee flexors play an important role in enhancing sprinting speed and stability in the execution of various motions involving the knee joint ${ }^{27}$. Chun et al. compared the isokinetic muscle strength characteristics of elite soccer players and non-athletes and reported that, the control group $(220.7 \pm 16.2 \mathrm{Nm})$ showed lower right extensor strength at $60 \% \mathrm{sec}$ compared to college $(260.4 \pm 16.1 \mathrm{Nm})$ and professional soccer players $(256.9 \pm 15.4 \mathrm{Nm})$, respectively ${ }^{28)}$. In addition, similar results were observed at $180 \% \mathrm{sec}$ suggesting that college and professional soccer players showed higher right extensor strength compared to the control group. These results were similar to the results of the present study that yielded statistically significant differences between the athlete and control groups.

Individuals with chronic ankle instability have diminished ROM due to lower-extremity muscle atrophy and postural imbalance; thus, they encounter problems with balance and walking, motions that comprise the basis for all physical activities. Furthermore, they are at high risk of recurrent injuries and functional movement limitations such as postural sway. A recent meta-analysis of ankle sprains and chronic ankle instability highlighted the need for an in-depth investigation of functional impairment causes and noted that diminished dynamic and static postural control ability can trigger earlier recurrence of ankle sprains ${ }^{11,29-31)}$. Ji et al. reported that the isokinetic peak torque of the ankle joint in concentric contraction showed significant differences between ankle instability and stability groups in a study of the impact of functional ankle instability on the strength of the muscle surrounding the ankle, balance ability, and functional performance; specifically, differences were observed in plantar flexor strength at $30 \% \mathrm{sec}, 60 \% \mathrm{sec}$, and $120 \% \mathrm{sec}$ and in plantar flexor and dorsiflexor strength at $30 \% \mathrm{sec}$ with respect to PTBW ${ }^{32}$ ). These results verified the high risk of recurrent functional instability due to ankle joint weakening. Moreover, the results are in line with those of the present study in which significant intergroup differences were demonstrated in the peak torque of left ankle dorsiflexor strength at $30^{\circ} / \mathrm{sec}$ and in peak torque of bilateral dorsiflexor strength and PTBW at a loading speed of $120^{\circ} / \mathrm{sec}$.

Gribble and Robinson compared the muscle strength of the ankle, knee, and hip joints with regard to the biomechanical and dynamic chain relationships to chronic ankle instability ${ }^{33)}$ and reported that the affected side showed significantly lower values than the healthy side in the isokinetic evaluation of plantar flexor (ankle) and flexor and extensor (knee) strength. In the present study, significant differences were demonstrated in peak torque, PTBW, and peak torque ratios in the plantar- and dorsiflexors and in the peak torque, PTBW, and peak torque ratios comparing plantar and dorsiflexors; significant differences between the healthy and affected sides were observed $(\mathrm{p}<0.001)$. These results are consistent with the values for isokinetic variables in a study by Kim and Jeon of 175 subjects with symptoms of chronic and functional ankle instability ${ }^{34)}$. These results also allow the conclusion that enhancing plantar and dorsiflexor strength will stimulate postural balance recovery ${ }^{35}$ ) and be conducive to securing ankle joint stability ${ }^{36,37)}$.

In conclusion, isokinetic evaluation stimulates muscle contraction at loading speeds based on ROM and carries a very low risk of exercise-induced injury. These valuable basic data will assist in the development of efficient and complex intervention programs to improve knee and ankle joint function according to injury degree and will ensure safety by correcting lowerextremity instability and muscle strength losses due to various causes.

\section{REFERENCES}

1) McKeon PO, Ingersoll CD, Kerrigan DC, et al.: Balance training improves function and postural control in those with chronic ankle instability. Med Sci Sports Exerc, 2008, 40: 1810-1819. [Medline] [CrossRef]

2) Fulkerson JP, Shea KP: Disorders of patellofemoral alignment. J Bone Joint Surg Am, 1990, 72: 1424-1429. [Medline]

3) Gross P, Marti B: Risk of degenerative ankle joint disease in volleyball players: study of former elite athletes. Int $\mathbf{J}$ Sports Med, 1999, 20: 58-63. [Medline] [CrossRef]

4) Boling MC, Bolgla LA, Mattacola CG, et al.: Outcomes of a weight-bearing rehabilitation program for patients diagnosed with patellofemoral pain syndrome. Arch Phys Med Rehabil, 2006, 87: 1428-1435. [Medline] [CrossRef]

5) Kim K, Hwang JH, Park WH: Effects of 4 weeks preoperative exercise on knee extensor strength after anterior cruciate ligament reconstruction. J Phys Ther Sci, 2015, 27: 2693-2696. [Medline] [CrossRef]

6) Anderson G, Herrington L: A comparison of eccentric isokinetic torque production and velocity of knee flexion angle during step down in patellofemoral pain syndrome patients and unaffected subjects. Clin Biomech (Bristol, Avon), 2003, 18: 500-504. [Medline] [CrossRef]

7) Mirzabeigi E, Jordan C, Gronley JK, et al.: Isolation of the vastus medialis oblique muscle during exercise. Am J Sports Med, 1999, 27: 50-53. [Medline]

8) LaBrier K, O’Neill DB: Patellofemoral stress syndrome. Current concepts. Sports Med, 1993, 16: 449-459. [Medline] [CrossRef]

9) Pattyn E, Mahieu N, Selfe J, et al.: What predicts functional outcome after treatment for patellofemoral pain? Med Sci 
Sports Exerc, 2012, 44: 1827-1833. [Medline] [CrossRef]

10) Wikstrom EA, Naik S, Lodha N, et al.: Balance capabilities after lateral ankle trauma and intervention: a meta-analysis. Med Sci Sports Exerc, 2009, 41: 1287-1295. [Medline] [CrossRef]

11) Smith LK, Weiss EL, Lehmkuhi LD: Brunnstrom's clinical kinesiology, 5th ed. Philadelphia: F.A. Davis, 1996, pp $162-167$.

12) Hertel J, Olmsted-Kramer LC: Deficits in time-to-boundary measures of postural control with chronic ankle instability. Gait Posture, 2007, 25: 33-39. [Medline] [CrossRef]

13) Hertel J: Functional anatomy, pathomechanics, and pathophysiology of lateral ankle instability. J Athl Train, 2002, 37: 364-375. [Medline]

14) Hopkins JT, Brown TN, Christensen L, et al.: Deficits in peroneal latency and electromechanical delay in patients with functional ankle instability. J Orthop Res, 2009, 27: 1541-1546. [Medline] [CrossRef]

15) Hoch MC, McKeon PO: Joint mobilization improves spatiotemporal postural control and range of motion in those with chronic ankle instability. J Orthop Res, 2011, 29: 326-332. [Medline] [CrossRef]

16) Beck TW, Housh TJ, Johnson GO, et al.: Effects of two days of isokinetic training on strength and electromyographic amplitude in the agonist and antagonist muscles. J Strength Cond Res, 2007, 21: 757-762. [Medline]

17) Möller M, Lind K, Styf J, et al.: The reliability of isokinetic testing of the ankle joint and a heel-raise test for endurance. Knee Surg Sports Traumatol Arthrosc, 2005, 13: 60-71. [Medline] [CrossRef]

18) Armour T, Forwell L, Litchfield R, et al.: Isokinetic evaluation of internal/external tibial rotation strength after the use of hamstring tendons for anterior cruciate ligament reconstruction. Am J Sports Med, 2004, 32: 1639-1643. [Medline] [CrossRef]

19) Nagai T, Sell TC, House AJ, et al.: Knee proprioception and strength and landing kinematics during a single-leg stopjump task. J Athl Train, 2013, 48: 31-38. [Medline]

20) Solgård L, Nielsen AB, Møller-Madsen B, et al.: Volleyball injuries presenting in casualty: a prospective study. Br J Sports Med, 1995, 29: 200-204. [Medline] [CrossRef]

21) Ott B, Cosby NL, Grindstaff TL, et al.: Hip and knee muscle function following aerobic exercise in individuals with patellofemoral pain syndrome. J Electromyogr Kinesiol, 2011, 21: 631-637. [Medline] [CrossRef]

22) Emrani A, Bagheri H, Hadian MR, et al.: Isokinetic strength and functional status in knee osteoarthritis. J Phys Ther Sci, 2007, 18: 107-114. [CrossRef]

23) Kang DY, Kim HS, Lee KS, et al.: The effects of bodyweight-based exercise with blood flow restriction on isokinetic knee muscular function and thigh circumference in college students. J Phys Ther Sci, 2015, 27: 2709-2712. [Medline] [CrossRef]

24) Kim CH: An analysis on Korean professional male volleyball players' injury parts and injury types in 2007/2008. Korean J Sports Sci, 2009, 18: 1253-1261.

25) Agel J, Palmieri-Smith RM, Dick R, et al.: Descriptive epidemiology of collegiate women's volleyball injuries: National Collegiate Athletic Association Injury Surveillance System, 1988-1989 through 2003-2004. J Athl Train, 2007, 42: 295-302. [Medline]

26) Lee JC, Kim JY, Park GD: Effect of 12 weeks of accelerated rehabilitation exercise on muscle function of patients with ACL reconstruction of the knee joint. J Phys Ther Sci, 2013, 25: 1595-1599. [Medline] [CrossRef]

27) Choi MR, Lee YC, Park SY, et al.: Isokinetic evaluation of the knee extensors and flexors in professional soccer players. Korean J Sports Sci, 2007, 16: 519-526.

28) Chun SY, Jeon KK, Park DS: The effect of composition and isokinetic knee and ankle strength of adult and elite football players. Korean J Sports Sci, 2012, 21: 1385-1395.

29) Munn J, Sullivan SJ, Schneiders AG: Evidence of sensorimotor deficits in functional ankle instability: a systematic review with meta-analysis. J Sci Med Sport, 2010, 13: 2-12. [Medline] [CrossRef]

30) Arnold BL, De La Motte S, Linens S, et al.: Ankle instability is associated with balance impairments: a meta-analysis. Med Sci Sports Exerc, 2009, 41: 1048-1062. [Medline] [CrossRef]

31) Cha YJ: Isokinetic training effect of ankle positions on knee extensor strength. J Phys Ther Sci, 2014, 26: $1465-1467$. [Medline] [CrossRef]

32) Ji SU, Kim HS, Kwon GU, et al.: The ankle strength, balance and functional ability of the adolescent volleyball players with functional ankle instability. Korean J Phys Educ, 2004, 43: 567-577. 
33) Gribble PA, Robinson RH: Alterations in knee kinematics and dynamic stability associated with chronic ankle instability. J Athl Train, 2009, 44: 350-355. [Medline] [CrossRef]

34) Kim KW, Jeon KK: Comparisons of static balance and gait, isokinetic muscular function of involved and non-involved side for chronic ankle instability. Korean J Sports Sci, 2015, 24: 1463-1472.

35) Kim BJ, Lee JH, Kim CT, et al.: Effects of ankle balance taping with kinesiology tape for a patient with chronic ankle instability. J Phys Ther Sci, 2015, 27: 2405-2406. [Medline] [CrossRef]

36) Kim KJ, Kim YE, Jun HJ, et al.: Which treatment is more effective for functional ankle instability: strengthening or combined muscle strengthening and proprioceptive. J Phys Ther Sci, 2014, 26: 385-388. [Medline] [CrossRef]

37) Son SM, Kang KW, Lee NK, et al.: Influence of isokinetic strength training of unilateral ankle on ipsilateral one-legged standing balance of adults. J Phys Ther Sci, 2013, 25: 1313-1315. [Medline] [CrossRef] 